\title{
CORRECTIONS
}

\section{Author Correction: mTOR at the nexus of nutrition, growth, ageing and disease}

\author{
Grace Y. Liu(D) and David M. Sabatini(i)
}

Nature Reviews Molecular Cell Biology (2020) https://doi.org/10.1038/s41580-019-0199-y Published online 14 January 2020

When discussing other nutritional inputs into mTORC1 (under the subheading 'Amino acids and other nutrients'), an additional reference (Ref. 281) was included, to acknowledge the work by Castellano et al. describing cholesterol as an activator of mTORC1 through a mechanism involving SLC38A9 and the Niemann-Pick C1 protein. The text has been corrected in the HTML and PDF versions of the article, and cholesterol has been added to Figure 3 to depict its role as an activator of mTORC1.

https://doi.org/10.1038/s41580-020-0219-y I Published online 31 January 2020

() Springer Nature Limited 2020 